\title{
LOW DENSITY POLYETHYLENE (LDPE) NANOCOMPOSITES WITH PASSIVE AND ACTIVE BARRIER PROPERTIES
}

\author{
MÓNICA A PÉREZ, ${ }^{a}$ BERNABÉ L RIVAS, ${ }^{a}$ KARLA A GARRIDO-MIRANDA ${ }^{a}$,VÍCTOR H. CAMPOS-REQUENA, ${ }^{a, b}$ \\ MIGUEL MARTÍNEZ ${ }^{c}$, JOHANNA CASTAÑNO ${ }^{d}$, ÁLVARO MALDONADO .
}

\author{
a) Department of Polymer, Chemical Sciences Faculty, University of Concepción, Casilla 160-C, Concepción, Chile. \\ b) Faculty of Pharmacy, University of Concepción, Casilla 160-C, Concepción, Chile. \\ c) Department of Microbiology, Biological Sciences Faculty, University of Concepción, Casilla 160-C, Concepción, Chile. \\ d) Unidad de Desarrollo Tecnológico, University of Concepción
}

\begin{abstract}
Nanocomposites based on Low Density Polyethylene (LDPE) containing organically modified montmorillonite (OMMT) and polyethylene grafted with maleic anhydride (PE-g-MA) were obtained by the mixing molten state method at $130{ }^{\circ} \mathrm{C}$ (LDPE / PE-g-MA / Cv / OMMT). Furthermore, in order to obtain a material with active barrier properties, carvacrol (Cv) was incorporated into the nanocomposite (LDPE / PE-g-MA / Cv / OMMT). Carvacrol is an essential oil component with a high antimicrobial, antifungal, and antiparasitic capability. The nanocomposites were characterized by XRD, DSC, TGA, oxygen permeability, and tensile test.

The nanocomposites without Cv (LDPE / PE- $g$-MA / OMMT) showed an intercalated morphology (confirmed by the X ray diffraction analysis), an improved percentage of crystallinity and a reduced permeability to oxygen $(25 \%)$ as compared with LDPE. The rigidity of the resulting material correlated with the clay content as expected.

The nanocomposite containing Cv (LDPE / PE-g-MA / Cv / OMMT) also show intercalated morphology with a greater displacement between the clay layers as compared with the nanocomposite without $\mathrm{Cv}$ produced by intercalation of the antimicrobial agent between the layers. The antimicrobial activity of (LDPE / PE-g-MA / Cv / OMMT) was observed by the reduction or inhibition on bacterial (Escherichia coli and Staphylococcus aureus) growth.
\end{abstract}

Keywords: Low Density Polyethylene; Nanocomposites; Carvacrol; Montmorillonite; Tensile properties; Crystallization; Oxygen permeability; Antimicrobial activity.

\section{INTRODUCTION}

Food container industry has shifted its focus from creating passive packaging to the development of active and intelligent barriers able to ensure the quality of the food during transport and storage. Intelligent or active packaging refer to the incorporation of additives (inside the container or integrated in the fabrication material) in order to maintain product quality and increase its lifetime[1]. Among others, oxygen scavengers, agents for moisture control, antimicrobial agents and antioxidants have been successfully used in active packaging.

Commonly used materials for the fabrication of food containers are metal, paper, glass, and polymers[2]. The great advantage of using polymers arrives from its functionality, light weight, ease of processing, low cost [3] and the possibility of fabricating either rigid or flexible packaging with straightforward experimental methodologies.. However, characteristics such as low gas barrier ability, low stiffness and no inhibition to bacterial growth limit their use in the fabrication of food containers. To improve the use of polymer several strategies are used (composites polymer blends, multilayer coatings and polymer film) but the high cost of production overcome the advantages obtained. One significant technological advance in the use of polymers in the packaging industry are nanocomposites

A polymer nanocomposite comprises, filler (clay), which has one of its dimensions in the nanometer range, the clay is dispersed as a reinforcement of a polymeric matrix. The montmorillonite used is a polar compound, therefore, it is only miscible with hydrophilic polymers in order to make it miscible with other polymers, the cations of the intermediate layers of the clay are exchanged organic molecules with a character (alkyl). Often the use of modified clays is not sufficient to improve the affinity clay - polymer, for this reason a compatibilizer which is a polymer modified with a polar group which interacts with the layers of clay and the non polar part is used to interact with the polymeric matrix, facilitating the intercalation of polymer between the clay layers, increasing the interlaminar space. Depending on the intercalation of the polymer and the clay dispersion morphological three states are possible, tactoid, interleaving, and exfoliated [4].

Polymer nanocomposites are prepared by different methods including in solution $[5,6]$ in-situ polymerization[7, 8], and melt blending $[9,10]$. The melt blending methodology is one of the most promising approaches since it does not requires solvent[11]. The process consists in dispersing the organoclay on the molten polymer $[12,13]$. Nanocomposites prepared using this methodology show a higher exfoliation level and the dispersion of the clay particles depends on the affinity between the polymer and the organic clay [14]

Among the advantages described for nanocomposites when compared with conventional materials used for packaging fabrication [15] the most relevant are: top gases barrier[16] and superior mechanical and thermal properties $[17,18]$. Even more, the possibility of adding component with antimicrobial activity into the nanocomposites enhances the superiority of these materials. Several reports show the success of this strategy using clays modified with copper[19], silver nanoparticles or zinc oxide ( $\mathrm{ZnO}$ ) [20] or natural antimicrobial compounds such as carvacrol and thymol[21,22]

Carvacrol $(\mathrm{Cv})$ is a phenolic monoterpene founded in the essential oil extracted from the oregano (Origanum vulgare L.) and possess antimicrobial and antifungal activity[23, 24]. This essential oil is considered as GRAS by the U.S. Food and Drug,[25] and therefore is considered non-harmful for food packaging fabrication. The antimicrobial activity of carvacrol nanocomposites have been reported using different polymeric matrix [21-23, 25, 26].<smiles>Cc1ccc(C(C)C)cc1O</smiles>

Structure Carvacrol (5-isopropyl-2-methylphenol).

The mechanism by which organisms eliminate carvacrol accomplished has not been fully defined[27], it is only to produce a history of changes in the membrane[28] leading to cell death[29]. The variation that produces about 4 fatty acids carvacrol was analyzed: Palmitic acid (C16: 0), cis-10heptadecanoic (C17: 1 cis), oleic acid (C18: 1cis) and R-linolenic acid (C18: 3 cis). When treated with carvacrol unsaturated fatty acids (C18: 1 cis and $\mathrm{C} 18$ : $3 \mathrm{cis})$ showed a large decrease, whereas palmitic acid (C16: 0) and cis-10heptadecanoic (C17: 1cis) increased[23].

On the other hand,Among the most important agents in food spoilage and also among the most important food-borne pathogens such as meat, dairy and vegetables are the bacteria Escherichia coli and Staphylococcus aureus. Food 
can be contaminated at any point in the production chain, the most important line contamination are composted manure to fields where they are grown and feces in irrigation water reaching the food product[30]

The main objectives of this research is to improve the barrier properties of the Low Density Polyethylene Nanocomposites (LDPE / PE-g-MA / OMMT) to be used for the fabrication of packaging material. We added Carvacrol to the nanocomposite (LDPE / PE-g-MA / Cv / OMMT) in order to change the properties from a passive to an active barrier. To evaluate the mechanical, thermal, morphological, and barrier characterisics of the nanocomposite LDPE / PE- $g$-MA / OMMT and the antimicrobial properties of LDPE / PE-g-MA / Cv / OMMT the following techniques were used DSC, TGA, gas permeability test.

\section{EXPERIMENTAL}

\section{Materials}

Low Density Polyethylene (LDPE) (MFI: $25 \mathrm{~g} / 10 \mathrm{~min}$ at $190^{\circ} \mathrm{C} / 2.16 \mathrm{~kg}$ and a density of $0.925 \mathrm{~g} / \mathrm{mL}$ at $25^{\circ} \mathrm{C}$ ), Organically Modified Montmorillonite (OMM), Nanomer ${ }^{\circledR}$ I.44P (surface modified montmorillonite clay with 35$45 \%$ by weight dimethyl dialkylammonium (C14-C18), and Carvacrol were purchased from Sigma-Aldrich. Polybond ${ }^{\circledR} 3149$ was provided by Chemtura (Brazil) and used without pretreatment. E. Coli K-12 and Staphylococcus aureus 6538- $p$ were from the culture collection of the Laboratory of Basic Microbiology and Bioremediation at the University of Concepción.

\subsection{Preparation of nanocomposites}

The nanocomposites were synthesized by the direct melting process method using an internal mixer (Proinco). A double heat pressing compression plate (Proinco) was used to fabricate nanocomposite films. The total mass of each formulation was $30.0 \mathrm{~g}$ Glycerol ( $2.0 \%$ by weight) was used as a release agent. The mixing speed was set at $60 \mathrm{rpm}$ and the mixing temperature was $130{ }^{\circ} \mathrm{C}$.

\section{Characterization}

\subsubsection{X-ray diffraction}

Patterns of X-ray diffraction was recorded with a Bruker AXS D4 Endeavor diffractomer, using $\mathrm{Cu}$ radiation $(40 \mathrm{kV}, 20 \mathrm{~mA})$ with a scan rate of 1 min- 1 for $2 \theta$ between $2^{\circ}$ and $30^{\circ}$ for montmorillonite clay (OMMT) and polymer nanocomposites. The distances between the interlayer spacing (d001) in the nanocomposites are calculated from the diffraction peak position using Bragg's law.

X-ray diffraction profiles for montmorillonite clay (OMMT) and polymer nanocomposites were recorded with a Bruker AXS D4 Endeavor diffractomer. A Cu radiation $(40 \mathrm{kV}, 20 \mathrm{~mA})$ was used with a scan rate of 1 min-1 using a $2 \theta$ angle range going from $2{ }^{\circ}$ to $30^{\circ}$. The distances between the interlayer spacing (d001) in the nanocomposites were calculated from the diffraction peak position using Bragg's law.

\subsubsection{Thermal Analysis}

The decomposition temperatures (Td) for LDPE and LDPE nanocomposite/ PE- -MA/ OMMT were obtained by thermogravimetric analysis (TGA) on a TGA 209 F1 Iris Equipment (Netzsch). Samples $(10 \mathrm{mg}$ ) placed in an alumina holder were submitted to a heating cycle at a rate of $10{ }^{\circ} \mathrm{C} / \mathrm{min}$ starting from room temperature $\left(25^{\circ} \mathrm{C}\right)$ up to $600{ }^{\circ} \mathrm{C}$, under nitrogen atmosphere. Melting behavior and crystallization of the nanocomposites was measured by differential scanning calorimetry (DSC) on a DSC 204 F1 Phoenix (Netzsch). The materials were heated from $25^{\circ} \mathrm{C}$ up to $300^{\circ} \mathrm{C}$ at a heating rate of $20^{\circ} \mathrm{C}$ $/$ min under nitrogen atmosphere. The peak melting temperature $(\mathrm{Tm})$ and the enthalpy of fusion (DHf) for the nanocomposites were obtained from the second heating curve, while the peak of crystallization temperature (Tc) was taken from the crystallization curve. Relative crystallinity was calculated from the value of enthalpy $\mathrm{DH}_{\mathrm{f}}$ using for $100 \%$ crystalline LDPE a theoretical value of enthalpy equal to $293 \mathrm{~J} / \mathrm{g}$ [31].

\subsubsection{Gas permeability test.}

The oxygen permeability tests for the nanocomposites LDPE / PE- $g$-MA / OMMT was performed at $23^{\circ} \mathrm{C}$ according to the standard test method ASTM D-3985 using a computer MOCON OX-TRAN Model 1/50. The exposed area of the film was $50 \mathrm{~cm}^{2}$ and the film thickness between 0.15 and $0.25 \mathrm{~mm}$.

\subsubsection{Tensile properties.}

Measurements of tensile test (stress strain) of the film samples were made at room temperature according to the standard test method ASTM D 638 using a universal testing machine model 005 Smartens (Karg Industrietechnik). Values of modulus of elasticity, yield strength and strain at break were obtained at a crosshead speed of $10 \mathrm{~mm} / \mathrm{min}$. The experimental values for tensile test are reported as an average of five measurements per sample.

\subsubsection{Antimicrobial test}

The antimicrobial effect of the LDPE and LDPE / PE- $g$-MA / OMMT and LDPE / PE-g-MA / Cv / OMMT nanocomposites were determined using Escherichia coli and Staphylococcus aureus. The method of ISO 22196 is designed to quantitatively evaluate the ability of the plastic to inhibit the growth of microorganisms over a period of 24 hours of contact. The method consists in that the quantified bacteria (105 colonies (CFU) / ml) are applied on the film having the antimicrobial, as well as the control film (no antimicrobial) for 24 hours, so as to meet the reduction bacterial load under the effect of existing antimicrobial surface. Finally the bacteria are removed from the surface and by the plate counting method the number of colony forming units of bacteria is determined, the assay was performed in triplicate.

\section{RESULTS AND DISCUSSION}

\subsection{Characterization of nanocomposites by X-Ray Diffraction (XRD).}

X-Ray Diffraction (XRD) is one of the techniques used to prove the formation of a nanocomposite. With this technique, the clay intercalation in the polymeric matrix can be determined by comparing the diffraction peak of the modified and unmodified material. The disappearance of diffraction peak indicates the possibility of exfoliation of the clay layers, while a shift of the pick towards lower angles of diffraction suggests an increase in the spacing between the layers, known as intercalation. The distance between the clay layers was calculated using Bragg's Law [32]

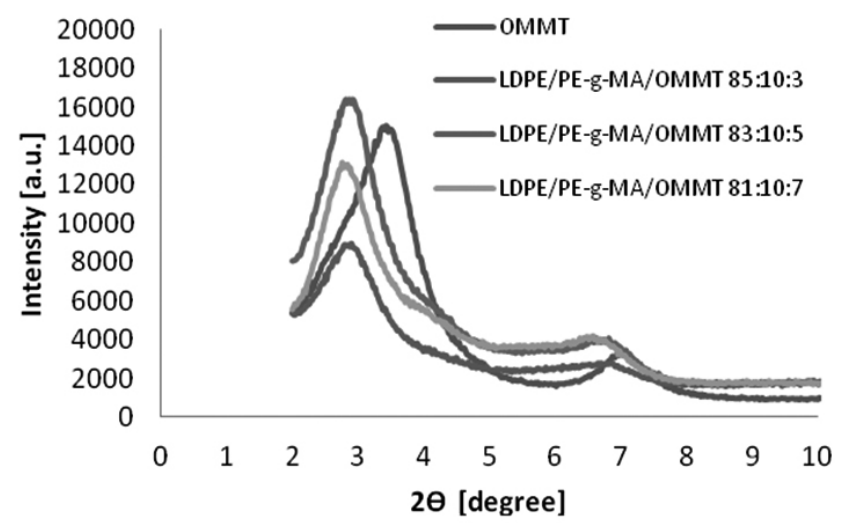

Figure 1. XRD patterns for OMMT, and nanocomposites LDPE/PE-gMA/OMMT prepared using melt mixing technique.

Figure 1 shows the XRD profiles fromOMMT and three representative samples of LDPE/ PE-g-MA/OMMT nanocomposites obtained using an internal mixer The diffractogram of the OMMT show an intense peak at $2 \mathrm{q}$ $=3.42^{\circ}$. This peak (peak 001) is characteristic of montmorillonite modified with alkyl group having a basal spacing of $d_{001}=25.8 \AA$. The three LDPE/ PE- $g$-MA/OMMT nanocomposites showed a displacement of the peak 001 at lower angles indicating that intercalation of the LDPE between the clay layers increased the spacing from $25.8 \AA$ to $30.7 \AA$. Beside this peak displacement, in two of the nanocomposites $(85 / 10 / 3$ and $81 / 10 / 7)$ the intensity of the peak decreased, which could indicate an intercalated/exfoliated [33] morphology for the obtained nanocomposites. The peak observed at about $7^{\circ}$ in the profiles shown in Figure 1 corresponds to the plane 002 of the clay and show similar displacement to lower angles in the case of the LDPE/PE-g-MA/OMMT nanocomposites.

3.2 Thermal, mechanical, and permeability properties of LDPE/PE-g-MA/ OMMT nanocomposites. 
The thermal properties of the samples were determined by DSC and TGA. Figure 2 show the second heating thermograms for LDPE and three samples of LDPE/PE-g-MA/OMMT. The thermograms from the nanocomposites showed a broader peak as compared with LDPE, indicating the mixing between the compatibilizer and the polymer. However, the melting temperature for the nanocomposites $\left(114+/-3{ }^{\circ} \mathrm{C}\right)$ did not change significantly from the one of the LDPE $\left(114^{\circ} \mathrm{C}\right)$ (see Table 1$)$.

if an increase occurs in the crystallization temperature in the nanocomposite LDPE / PE-g-MA / OMMT 85:10:3, compared to LDPE processed, which is due to the silicate layers induce nucleation and crystals may start to grow at higher temperatures for Tc, opposite effect between PE-g-MA and LDPE [34]

The crystallinity of the nanocomposites and LDPE was calculated assuming a theoretical value of $293 \mathrm{~J} / \mathrm{g}$ [31] for the heat involved in the fusion of a completely crystalline polymer, in which an increase of $15 \%$ for the nanocomposite was obtained 85:10:3, as a result of which tends to a morphology exfoliated intercalated clay produces that is located more spread and therefore are more effective nucleation sites for crystallization[35]

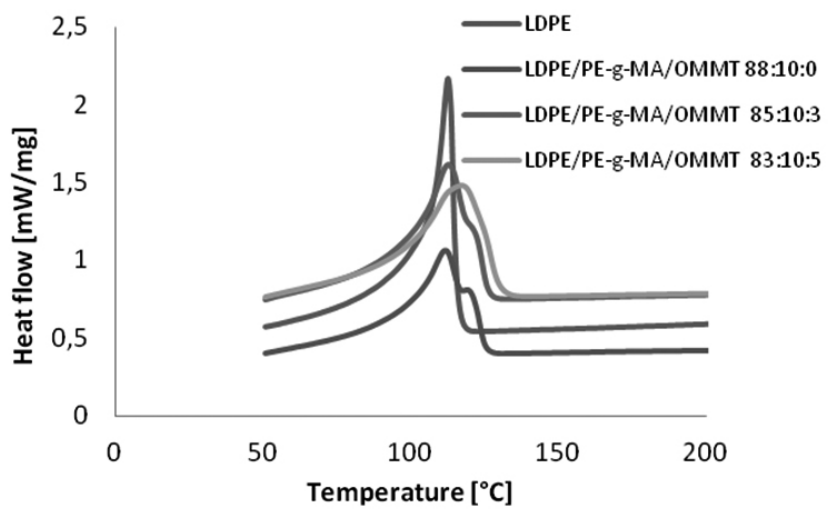

Figure 2. DSC thermograms, second heating curve for neat LDPE and LDPE/PE-g-MA/OMMT nanocomposites.

Figure 3 shows the decomposition profile (percentage of weight loss with temperature) for LDPE and LDPE / PE- $g$-MA / OMMT nanocomposites performed in one step The presence of clay in the nanocomposite confers thermal stability to it shown by the continuous shifting of the curve to higher temperatures as the clay content increased, as it is also shown in Table 1. These results may be attributed to the silicate layers acting as an insulator and a barrier to mass transport from volatiles substances generated during the decomposition [36].

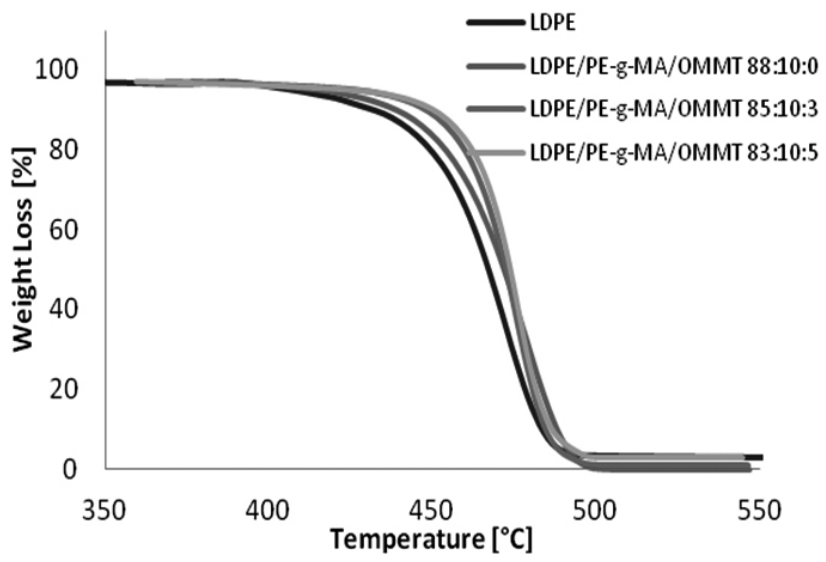

Figure 3. TGA curves of neat LDPE and LDPE/PE- $g$-MA/OMMT nanocomposites under nitrogen flow.
Table 1. DSC and TGA results for the LDPE and LDPE/PE- $g$-MA/ OMMT nanocomposites, and crystallinity degree.

\begin{tabular}{|c|c|c|c|c|c|c|}
\hline $\begin{array}{c}\text { LDPE/PE- } g- \\
\text { MA/OMMT }\end{array}$ & $\begin{array}{c}\mathrm{Td}^{\mathrm{a})} \\
{\left[{ }^{\circ} \mathrm{C}\right]}\end{array}$ & $\begin{array}{c}\mathrm{T}_{10 \%}{ }^{\mathrm{b})} \\
{\left[{ }^{\circ} \mathrm{C}\right]}\end{array}$ & $\begin{array}{c}\mathrm{T}_{50 \%}{ }^{\mathrm{c}} \\
{\left[{ }^{\circ} \mathrm{C}\right]}\end{array}$ & $\begin{array}{c}\mathrm{Tm}^{\mathrm{d})} \\
{\left[{ }^{\circ} \mathrm{C}\right]}\end{array}$ & $\begin{array}{c}\mathrm{Tc}^{\mathrm{e})} \\
{\left[{ }^{\circ} \mathrm{C}\right]}\end{array}$ & $\mathrm{c}_{\mathrm{c}}{ }^{\mathrm{f}}[\%]$ \\
\hline $\mathbf{9 8 / 0 / 0}$ & $\mathbf{4 6 9}$ & $\mathbf{4 3 0}$ & $\mathbf{4 6 5}$ & $\mathbf{1 1 4}$ & $\mathbf{9 5 . 8}$ & $\mathbf{4 1 . 6}$ \\
\hline $\mathbf{8 8} / 10 / 0$ & $\mathbf{4 8 0}$ & $\mathbf{4 3 7}$ & $\mathbf{4 7 2}$ & $\mathbf{1 1 2}$ & $\mathbf{9 9 . 7}$ & $\mathbf{3 6 . 8}$ \\
\hline $\mathbf{8 5 / 1 0 / 3}$ & $\mathbf{4 7 6}$ & $\mathbf{4 4 6}$ & $\mathbf{4 7 1}$ & $\mathbf{1 1 3}$ & $\mathbf{9 8 . 4}$ & $\mathbf{4 7 . 8}$ \\
\hline $\mathbf{8 3 / 1 0 / 5}$ & $\mathbf{4 7 7}$ & $\mathbf{4 5 0}$ & $\mathbf{4 7 2}$ & $\mathbf{1 1 7}$ & $\mathbf{9 4 . 9}$ & $\mathbf{4 6 . 8}$ \\
\hline
\end{tabular}

a) Decomposition Temperature

b) $\mathrm{T}_{10 \%}$, Temperature at which $10 \%$ of weight loss occurs

c) $\quad \mathrm{T}_{50 \%}, \mathrm{~T}, \mathrm{Temperature}$ at which $50 \%$ of weight loss occurs

d) Tm, Melting Temperature

e) Tc, Crystalization Temperature

f) $\mathrm{c}_{\mathrm{c}}=\mathrm{DH}_{\mathrm{m}} \mathrm{DH}^{\circ} \times 100 \%, \mathrm{DH}_{\mathrm{m}}$ Melting enthalpy of sample, $\mathrm{DH}^{\circ} \mathrm{m}=$ Melting enthalpy of pure crystalline LDPE $(293 \mathrm{~J} / \mathrm{g})[31]$.

The results of the tensile test for LDPE and LDPE/PE- $g$-MA/OMMT nanocomposites are shown in Table 2 . The elastic modulus increases with the clay content, 12 and $25 \%$ for nanocomposite $85 / 10 / 3$ and 83/10/5 respectively. Reports in the literature show a direct relationship between the increase in elastic modulus and the interlaminar distance of the clay [37], however in our case the nanocomposites exhibit the same interlaminar distance is for this reason that the improvement is attributable to the content of clay, in which silicate layers are those that limit the movement of the polymer chains so nanocomposites are stiffer than LDPE neat[38]

The parameters of stress at break and tensile strength are not dependent on the clay content level if so scatter silicate layers[16].

Table 2. Tensile properties of LDPE neat and LDPE/PE-g-MA/OMMT nanocomposites.

\begin{tabular}{|c|c|c|c|c|c|}
\hline $\begin{array}{c}\text { LDPE/ } \\
\text { PE-g-MA/ } \\
\text { OMMT }\end{array}$ & $\begin{array}{c}\text { Elastic } \\
\text { modulus } \\
{[\mathrm{Mpa}]}\end{array}$ & $\begin{array}{c}\text { Yield } \\
\text { stress } \\
{[\mathrm{MPa}]}\end{array}$ & $\begin{array}{c}\text { Tensile } \\
\text { Strength } \\
{[\mathrm{MPa}]}\end{array}$ & $\begin{array}{c}\text { Stress } \\
\text { at break } \\
{[\mathrm{MPa}]}\end{array}$ & $\begin{array}{c}\text { Elongation } \\
\text { at break } \\
\text { standard } \\
{[\%]}\end{array}$ \\
\hline $98 / 0 / 0$ & $182 \pm 24$ & $1.6 \pm 2.1$ & $13.4 \pm 1.1$ & $6.8 \pm 2.2$ & $46.4 \pm 2.5$ \\
\hline $85 / 10 / 3$ & $204 \pm 33$ & $1.8 \pm 2.1$ & $14.9 \pm 0.9$ & $7.7 \pm 2.5$ & $36.1 \pm 8.9$ \\
\hline $83 / 10 / 5$ & $227 \pm 29$ & $2.4 \pm 0.2$ & $13.6 \pm 0.2$ & $4.6 \pm 0.8$ & $37.3 \pm 3.5$ \\
\hline
\end{tabular}

The oxygen permeability results for films fabricated with LDPE neat and LDPE / PE-g-MA / OMMT nanocomposites are listed in Table 3. Nanocomposites $85 / 10 / 3$ and $83 / 10 / 5$ showed a decreased oxygen permeability ( $27 \%$ and $20 \%$ respectively) as compared to LDPE neat. Contrary to reported data in the literature, we did not found a correlation between the barrier properties and the clay content $[4,9]$. Three are three factors affecting the permeability to gas in a given material: the degree of crystallinity, the polarity, and the structure of the the polymer[16]. The two nanocomposites characterized in this work have the same polymeric matrix (LDPE), same compatibilizing agent at equal concentration, so that the polarity increases in both cases in the same way. The difference is given by the crystallinity parameter, for instance nanocomposite $85 / 10 / 3$ show a higher crystallinity and consequently the largest decrease in oxygen permeability. In this manner, the crystalline regions of the material and the clay content hinders the passage of the oxygen molecules[39] through the material.

Table 3. Oxygen permeability data of LDPE neat and LDPE/PE- $g$-MA/ OMMT nanocomposites.

\begin{tabular}{|c|c|}
\hline LDPE/PE-g-MA/OMMT & $\mathrm{O}_{2}$ permeability $\left[\mathrm{cm}^{3} /\left(\mathrm{m}^{2}\right.\right.$ day $)$ atm $]$ \\
\hline $\mathbf{9 8 / 0 / 0}$ & $\mathbf{2 6 0} \pm \mathbf{6}$ \\
\hline $\mathbf{8 5 / 1 0 / 3}$ & $\mathbf{1 8 9} \pm \mathbf{2 4}$ \\
\hline $\mathbf{8 3 / 1 0 / 5}$ & $\mathbf{2 1 0} \pm \mathbf{5}$ \\
\hline
\end{tabular}

3.3 LDPE/PE-g-MA/Cv/OMMT Nanocomposites.

For the development of films with antimicrobial activity, the nanocomposite 
$85 / 10 / 3$ I present the best thermal and barrier properties was selected. Carvacrol concentrations of $5 \% \mathrm{~m} / \mathrm{m}$ and $10 \% \mathrm{~m} / \mathrm{m}$ was used in the LDPE / PE-g-MA / Cv / OMMT nanocomposites

LDPE / PE-g-MA / Cv / OMMT nanocomposites were studied by DSC, TGA, and XRD , and the results are shown in Table 4. The probability of carvacrol intercalation between the layers of silicate was examined by DRX. A mechanical mixture of clay / carvacrol in a 3:5 ratio was prepared and submitted to $100{ }^{\circ} \mathrm{C}$ for $10 \mathrm{~s}$. A XRD d $\mathrm{d}_{001}$ value of $35.34 \AA$ indicate that carvacrol is efficiently sandwiched between layers of clay and producing an increase in the distance between the silicate layers of 37\%. For LDPE / PE-g- MA / Cv / OMMT nanocomposites a $\mathrm{d}_{001}$ of approximately $38.75 \AA$ is observed (see Table 4), thus the polymer - carvacrol mixture produces a synergistic effect, increasing the distance between the layers silicate up to $50 \%$ with respect to the clay. Carvacrol which is between the layers of clay allows slow release occurs into the environment[21]. Figure 4 shows the diffractogram $\mathrm{Cv} / \mathrm{OMMT}$ observed as carvacrol causes delamination of the clay, the plane 002 and appear 003, which is still observed in the LDPE / PE-g-MA / Cv / OMMT nanocomposites.

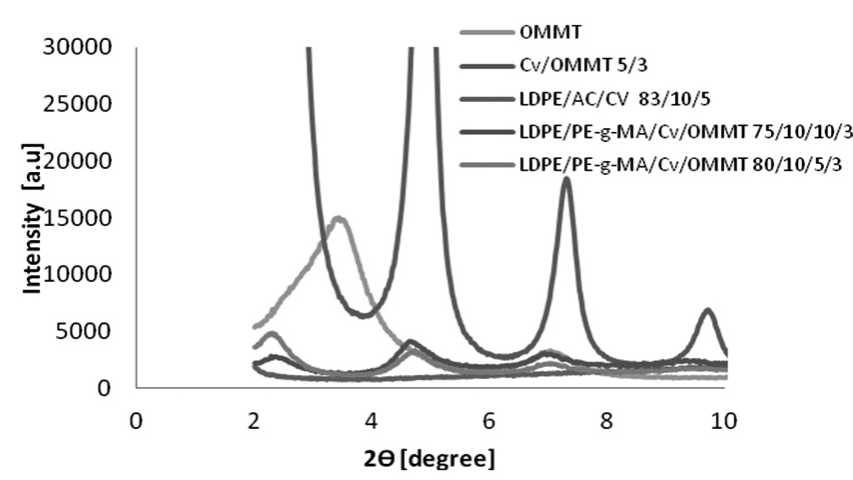

Figure 4. XRD patterns of OMMT, Cv/OMMT and nanocomposites LDPE/PE-g-MA/Cv/OMMT.

The thermal stability LDPE / PE- $g$-MA / Cv / OMMT was studied by TGA. From the results obtained, T10\% value (temperature when you have lost $10 \%$ by mass) of the nanocomposite $75 / 10 / 10 / 3$ has the lowest temperature which can be explained because it is the one with the highest content of carvacrol, which decomposes mostly in a range between $140{ }^{\circ} \mathrm{C}$ to $230{ }^{\circ} \mathrm{C}$ which easily happens if the carvacrol is not between the clay layers 25 . As it was described in section 2.3, we know the percentage of crystallinity as the clay content since both are what determine the degree of oxygen permeability. The crystallinity values are shown in Table 4 for the LDPE / PE-g-MA / Cv / OMMT percent crystallinity nanocomposites are closer to the nanocomposite LDPE LDPE / PE-g-MA / OMMT where obtained a percent crystallinity of $43.1 \%$ for the nanocomposite $75 / 10 / 10 / 3$ also exhibits an increase in crystallinity with temperature incorporating carvacrol.

Table 4. Morphological and thermal properties.

\begin{tabular}{|c|c|c|c|c|c|c|c|}
\hline $\begin{array}{c}\text { LDPE/PE- } \\
\text { g-MA/Cv/ } \\
\text { OMMT }\end{array}$ & $\begin{array}{c}\mathrm{Td}^{\mathrm{a})} \\
{\left[{ }^{\circ} \mathrm{C}\right]}\end{array}$ & $\begin{array}{c}\left.\mathrm{T}_{10 \%}{ }^{\mathrm{b}}\right) \\
{\left[{ }^{\circ} \mathrm{C}\right]}\end{array}$ & $\begin{array}{c}\left.\mathrm{T}_{50 \%}{ }^{\mathrm{c}}\right) \\
{\left[{ }^{\circ} \mathrm{C}\right]}\end{array}$ & $\begin{array}{c}\left.\mathrm{Tm}^{\mathrm{d}}\right) \\
{\left[{ }^{\circ} \mathrm{C}\right]}\end{array}$ & $\begin{array}{c}\left.\mathrm{Tc}^{\mathrm{e}}\right) \\
{\left[{ }^{\circ} \mathrm{C}\right]}\end{array}$ & $\begin{array}{c}\mathrm{c}_{\mathrm{c}}^{\mathrm{f}} \\
{[\%]}\end{array}$ & $\begin{array}{c}\mathrm{d}_{001} \\
{[\AA]}\end{array}$ \\
\hline $98 / 0 / 0 / 0$ & 469 & 430 & 465 & 114 & 95.8 & 41.6 & 25.83 \\
\hline $85 / 10 / 0 / 3$ & 476 & 446 & 471 & 113 & 98.4 & 47.8 & 30.48 \\
\hline $80 / 10 / 5 / 3$ & 474 & 433 & 469 & 110 & 98.9 & 40.4 & 38.75 \\
\hline $75 / 10 / 10 / 3$ & 472 & 360 & 467 & 109 & 105.9 & 43.1 & 38.42 \\
\hline
\end{tabular}
a) Decomposition Temperature
b) $\mathrm{T}_{10 \%}$, Temperature at which $10 \%$ of weight loss occurs
c) $\quad \mathrm{T}_{50 \%} 0 \%$, Temperature at which $50 \%$ of weight loss occurs
d) $\quad \mathrm{Tm}$, Melting Temperature
e) Tc, Crystalization Temperature
f) $\quad \mathrm{c}{ }^{=} \mathrm{DH}_{\mathrm{m}} \mathrm{DH}^{\circ}{ }_{\mathrm{m}} \times 100 \%$, DH ${ }_{\mathrm{m}}$ Melting enthalpy of sample, $\mathrm{DH}^{\circ} \mathrm{m}=$ Melting enthalpy of pure crystalline LDPE $(293 \mathrm{~J} / \mathrm{g})[31]$.

3.1.2 Antimicrobial ACtivity

The antimicrobial activity of LDPE neat, LDPE / PE- $g$ - MA / OMMT and LDPE / PE-g- MA / Cv / OMMT was analyzed using E. coli and S. aureus. Figure 5 shows the bacterial growth in the films after $24 \mathrm{~h}$ in contact with the bacteria at $30^{\circ} \mathrm{C}$. The initial concentration for E. coli and S. aureus was set at approximately $5.58 \times 105[\mathrm{CFU} / \mathrm{mL}]$ and $5.05 \times 105[\mathrm{CFU} / \mathrm{mL}]$ respectively. It is observed that the LDPE neat and LDPE / PE- $g$-MA / OMMT exhibit bacterial growth, which is higher for the nanocomposite in the two types of assessment bacteria, this increase could be attributable to an environment rich in oxygen and carbon dioxide, as the clay layers but impede the passage of gases, they are trapped in the films, so to get in direct contact with the bacteria, most likely you are able to use these gases trapped to encourage their growth. Instead of LDPE / PE- $g$-MA / Cv / OMMT nanocomposites successfully eliminate and inhibit bacterial growth of E. coli and S. aureus which $100 \%$ is attributed to the antimicrobial effects of carvacrol.

Although the focus of this research is not the mechanism of action carvacrole, there are some reports indicating membrane alteration and cellular death as the mechanisms by which carvacol eliminates microorganisms[27, 29]

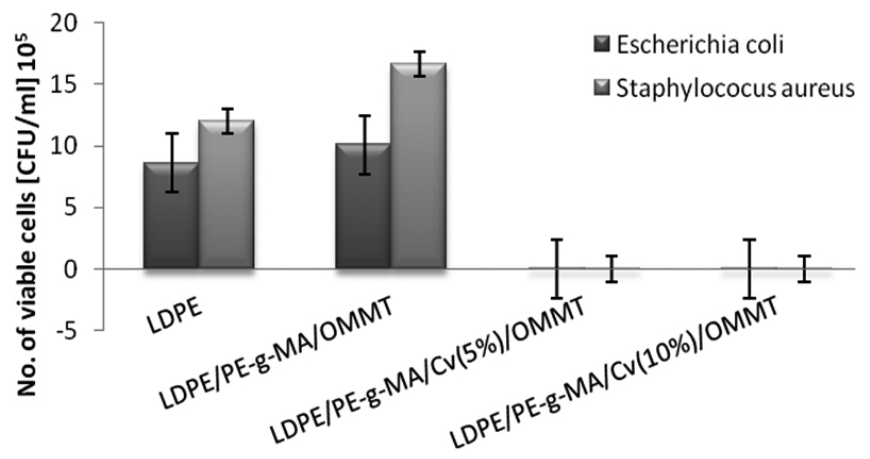

Figure 5. Antimicrobial activity of LDPE neat, LDPE/PE-g-MA/OMMT, and LDPE/PE- $g$-MA/Cv/OMMT after $24 \mathrm{~h}$.

\section{CONCLUSIONS}

LDPE / PE-g-MA / OMMT nanocomposites were obtained by the melt mixing method in an internal mixer The intercalated nanocomposite morphology exhibited as confirmed by X-ray diffraction, in which the characteristic diffraction peak of the clay in all cases moves $2 \mathrm{j}$ lower angles. An increase in the elastic modulus so that a stiffer material is obtained with higher clay content can be observed. The thermal properties and the decomposition temperature produced at higher temperatures in an inert atmosphere, the crystallinity increases, which occurs due to the nucleating effect of the clay. The improvement in the crystallinity by clay content are factors that reduce oxygen permeability respect to polymer processing.

The LDPE / PE-g-MA / Cv / OMMT nanocomposites exhibit antimicrobial activity against the bacteria $E$. coli and $S$. aureus reaching a $99 \%$ reduction in the number of colonies to be in contact with the film for $24 \mathrm{~h}$. X-ray diffraction showed that the carvacrol is sandwiched between layers of clay easily improving the dispersion of clay layers.

In addition, it was achieved the obtention of an enhanced passive barrier material and active barrier material, which can project the possible application of the nanocomposite films as food packaging materials.

\section{ACKNOWLEDGMENTS}

The authors thank FONDEF (Grant No DI0i1234), REDOC (MINEDUC Project UCO1202 at U. de Concepción) and CONICYT REGIONAL CIPA (Centro de Investigación de Polímeros Avanzados) R08C1002

\section{REFERENCES}

1. Kerry. J.P, O.M.N., Hogan. S.A, Past, current and potential utilisation of active and intelligent packaging systems for meat and muscle-based products: A review. Meat Sci, 2006. 74(1): p. 113-130.

2. Marsh. K, B.B., Food packaging--roles, materials, and environmental issues. J Food Sci, 2007. 72(3): p. 39-55. 
3. Arora. A, P.G.W., Review: nanocomposites in food packaging. J Food Sci., 2010. 75(1): p. 43-49.

4. Hotta. S, P.D., Nanocomposites formed from linear low density polyethylene and organoclays. Polymer, 2004. 45: p. 7639-7654.

5. Ogata. N, K.S., Ogihara. T, Poly(vinyl alcohol)-clay and poly(ethylene oxide)-clay blends prepared using water as solvent. J. Appl. Polym. Sci., 1997. 66(3): p. 573-581.

6. Yano. K, U.A., Okada. A, Kurauchi. T, Kamigaito. O, Synthesis and properties of polyimide-clay hybrid. J. Polym. Sci. Part A Polym. Chem., 2003. 31(10): p. 2493-2498.

7. Lomakin. S, N.L., Brevnov. P, Shchegolikhin.A, Thermal properties of polyethylene/montmorillonite nanocomposites prepared by intercalative polymerization. J. Mater. Sci., 2008. 43(4): p. 1340-1353.

8. Heinemann. J, R.P., Thomann. R, Mülhaupt. R, Polyolefin nanocomposites formed by melt compounding and transition metal catalyzed ethene homoand copolymerization in the presence of layered silicates. Macromol. Rapid Commun., 1999. 20(8): p. 423-430.

9. Lee. J, J.D., Hong C, Rhee K, Advani. S, Properties of polyethylenelayered silicate nanocomposites prepared by melt intercalation with a PPg-MA compatibilizer. Compos. Sci. Technol, 2005. 65(13): p. 1996-2002.

10. Ali Dadfar. S, A.I., Reza Dadfar. S, Vosoughi. M, Studies on the oxygen barrier and mechanical properties of low density polyethylene/organoclay nanocomposite films in the presence of ethylene vinyl acetate copolymer as a new type of compatibilizer. Mater. Des., 2011. 32(4): p. 1806-1813.

11. Di. Y, I.S., Maio. E, Nicolais.L, Nanocomposites by melt intercalation based on polycaprolactone and organoclay. J. Polym. Sci. Part B Polym. Phys., 2003. 41(7): p. 670-678.

12. Vaia. R, I.H., Giannelis. E, Synthesis and properties of two-dimensional nanostructures by direct intercalation of polymer melts in layered silicates. Chem. Mater, 1993. 5(12): p. 1694-1696.

13. Vaia. R, J.K., Kramer.E, Giannelis. E, Kinetics of Polymer Melt Intercalation. Macromolecules, 1995. 28: p. 8080-8085.

14. Chavarria. F, S.R., Effect of melt processing conditions on the morphology and properties of nylon 6 nanocomposites. Polym. Eng. Sci, 2007. 47(11): p. $1847-1864$

15. Duncan. T, Applications of nanotechnology in food packaging and food safety: Barrier materials, antimicrobials and sensors. J. Colloid Interface Sci, 2011. 363: p. 1-24.

16. Zhong.Y, J.D., Zheng. Y, Hetzer. M, De Kee. D, Mechanical and oxygen barrier properties of organoclay-polyethylene nanocomposite films. Polym. Eng. Sci., 2007. 47(7): p. 1101-1107.

17. Teymouri. Y, N.H., The effect of process parameters on physical and mechanical properties of commercial low density polyethylene/ORGMMT nanocomposites. J. Mater. Sci., 2011. 46(20): p. 6642-6647.

18. Lomakin. S, D.I., Shchegolikhin. A, Zaikov. G, Kozlowski. R, Kim. $\mathrm{G}$, Michler. G, Thermal degradation and combustion behavior of the polyethylene/clay nanocomposite prepared by melt intercalation. Journal of Thermal Analysis and Calorimetry, 2008. 94(3): p. 719-726.

19. Bruna. J, P.A., Guarda. A, Rodríguez. F, Galotto. M, Development of $M t C u 2+/ L D P E$ nanocomposites with antimicrobial activity for potential use in food packaging. Appl. Clay Sci, 2012. 58: p. 79-87.

20. Emamifar. A, K.M., Shahedi. M, Soleimanian-Zad. S, Evaluation of nanocomposite packaging containing $\mathrm{Ag}$ and $\mathrm{ZnO}$ on shelf life of fresh orange juice. Innov. Food Sci. Emerg. Technol., 2010. 11(4): p. 742-748.
21. Tunç. S, D.O., Preparation of active antimicrobial methyl cellulose/ carvacrol/montmorillonite nanocomposite films and investigation of carvacrol release. LWT - Food Science and Technology, 2011. 44(2): p. 465-472.

22. Sanchez-Garcia. M, G.E., Lagaron, J, Morphology and barrier properties of nanobiocomposites of poly(3-hydroxybutyrate) and layered silicates. J. Appl. Polym. Sci., 2008. 108(5): p. 2787-2801.

23. Pasqua. R, B.G., Hoskins. N, Edwards. M, Ercolini. D, Mauriello. G, Membrane toxicity of antimicrobial compounds from essential oils. J. Agric. Food Chem, 2007. 55(12): p. 4863-4870.

24. Lima. I, P.F., De Oliveira. W, Lima. E, Menezes. E, Cunha. F, Diniz. M, J. Essent. Oil Res, 2013. 25: p. 138-142.

25. López. P, S.C., Batlle. R, Nerín. C, Vapor-Phase Activities of Cinnamon, Thyme, and Oregano Essential Oils and Key Constituents against Foodborne Microorganisms. J. Agric. Food Chem, 2007. 55(11): p. 43484356.

26. Persico. P, A.V., Carfagna. C, Cerruti. P, Ferrocino. I, Mauriello. G, Nanocomposite polymer films containing carvacrol for antimicrobial active packaging. Polym. Eng. Sci, 2009. 49(7): p. 1447-1455.

27. Veldhuizen. E, T.-v.B.J., Zweijtzer. C Burt.S, Haagsman. H, Structural Requirements for the Antimicrobial Activity of Carvacrol. J. Agric. Food Chem, 2006. 54: p. 1874-1879.

28. Burt. S, Essential oils: their antibacterial properties and potential applications in foods - a review. Int. J. Food Microbiol., 2004. 94: p. 223253.

29. Pasqua R, H.N., Betts. G, Mauriello. G, Changes in Membrane Fatty Acids Composition of Microbial Cells Induced by Addiction of Thymol, Carvacrol, Limonene, Cinnamaldehyde, and Eugenol in the Growing Media. J. Agric. Food Chem., 2006. 54: p. 2745-2749.

30. Franz. E, V.B.A., Ecology of E. coli O157:H7 and Salmonella enterica in the primary vegetable production chain. Crit Rev Microbiol., 2008

34: p. 143-161

31. Wunderlich. B , C.G., A Study of Equilibrium Melting of Polyethylene. Macromolecules, 1977. 10(5): p. 906-913.

32. Sperling, L.H., Introduction to Physical Polymer Science, , ed. J.W. Sons. Vol. 2005. 2005.

33. Horst. M, Q.L., Failla. M, Rheological and barrier properties of nanocomposites of HDPE and exfoliated montmorillonite. J. Thermoplast. Compos. Mater., , 2012. 27(1): p. 106-125.

34. Giannakas. A, X.P., Preparation and characterization of polymer/ organosilicate nanocomposites based on unmodified LDPE. J. Appl. Polym. Sci., 2009. 114(1): p. 83-89.

35. Morawiec. J, P.A., Slouf. M, Galeski. A, Piorkowska. E, Krasnikowa. $\mathrm{N}$, Preparation and properties of compatibilized LDPE/organo-modified montmorillonite nanocomposites. Eur. Polym. J., 264. 41: p. 1115-1122.

36. Pavlidou. S, P.C., A review on polymer-layered silicate nanocomposites. Prog. Polym. Sci., 2008. 33: p. 1119-1198.

37. Popli. R, M.L., Influence of structural and morphological factors on the mechanical properties of the polyethylenes. J. Polym. Sci. Part B Polym. Phys., 2003. 25(3): p. 441-483.

38. Paul. D, R.L., Polymer nanotechnology: Nanocomposites. Polymer, 2008 : p. 3187-3204.

39. Liz. L, Nanometals: Formation and color. Mater. Today, 2004. 7: p. 2631. 